\title{
MUSEOLOGIA, CAMPO DISCIPLINAR DA MUSEALIZAÇÃO E FUNDAMENTOS DE INFLEXÃO SIMBÓLICA: 'TEMATIZANDO' BOURDIEU PARA UM CONVITE À REFLEXÃO'
}

\author{
Diana Farjalla Correia Lima ${ }^{2}$ \\ Universidade Federal do Estado do Rio de Janeiro (UNIRIO)
}

\begin{abstract}
RESUMO:
Análise do campo museológico retratando seu perfil teórico e prático como instaurador do poder simbólico: a musealização do(s) patrimônio(s). Aplicação da Teoria Geral da Economia dos Campos, perspectiva de Pierre Bourdieu, interpretando as representações construídas, significações expressas, relações estabelecidas e as variadas circunstâncias no ambiente social da forma cultural Museu. Indicadores analíticos abordaram as peculiaridades do campo associadas a bens culturais, entidades/instituições e profissionais no modelo cultural da apropriação simbólica. Destaque para juízos/atitudes enlaçando conceitos de distinção, competência, legitimidade dos profissionais de museu e instâncias institucionais no jogo das estratégias de fortalecimento das fronteiras disciplinares e manutenção do exercício de poder simbólico.
\end{abstract}

\section{PALAVRAS-CHAVE:}

Musealização. Museu. Poder Simbólico. Campo do conhecimento. Interdisciplinaridade.

\begin{abstract}
:
Analysis of the museological field depicting its theoretical and practical profile as a space that establishes the symbolic power: the musealization of symbolic assets (cultural heritage). The research uses the General Theory of Economy of Fields (Bourdieu), interpreting the representations, meanings, relationships and the varied circumstances' of the Museum image in social environment. Analytical indicators discussed the peculiarities of the field associated with cultural objects, entities/institutions and professionals in the cultural model of symbolic appropriation. Emphasis on judgments/attitudes linking concepts of competence, legitimacy of museum professionals and institutional instances in the set of strategies for strengthening disciplinary boundaries and maintenance of symbolic power.
\end{abstract}

KEY-WORDS:

Musealization. Museum. Symbolic Power. Field of knowledge. Interdisciplinarity.

I Pesquisa, apoio CNPq (produtividade): Musealização e Patrimonialização - Termos e Conceitos da Museologia em ação: identificando e explicitando indicadores teórico-práticos para aplicação.

2 Museóloga (graduação: Museus Artísticos, 1975; Museus Históricos, 1976) Museu Histórico Nacional, (MHN)/UFRJ; mestrado: Memória Social e Documento UNIRIO (1996); doutorado: Ciência da Informação, IBICT/ECO-UFRJ (2003). Professora: Curso de Graduação em Museologia, UNIRIO, e Programa de Pós-Graduação em Museologia e Patrimônio UNIRIO/MAST. 


\section{Iniciando...}

Ao focalizar-se o universo museológico, o seu aparato conceitual e técnico como campo do conhecimento e a construção cultural que o anima e constitui sua representação essencial: o Museu, bem simbólico, cabe em razão de tal caráter abordar a questão do sentido simbólico, postura que leva a compreender a dimensão da cultura como meio aglutinador das disposições sociais. E reconhecer que as significações relacionadas constituem "mensagens vinculadas aos objetos, instrumentos e agentes do campo que demarcam o espaço arbitrário no qual evoluem" (LIMA, 2000, p. 30) os grupos sociais diferenciados cujas origens são encontradas no exercício do "poder simbólico" (BOURDIEU, 1989). Também, do mesmo modo, ter em conta que as significações representam "o poder dominante na construção das realidades dos grupos sociais" (LIMA, 2003, p. 44), portanto, exercendo presença ativa com lastro no espaço social, cenário de inserção dos campos.

O conjunto interpretativo produzido consubstancia o código cultural de comunicação estabelecido pelos grupos sociais que enunciam a construção do mundo dos objetos. E a compreensão do mundo calcada nas múltiplas formas de percepção do real comporta distintos significados explicativos, assim como traça linhas buscando definir espaços correspondentes às respectivas áreas de significação que, no assunto em questão, conformam-se como campos do conhecimento, domínios, áreas, territórios, espaços do saber/saberes.

Em se tratando de domínios do conhecimento e no bojo do processo que os identifica simbolicamente como ambientes construídos segundo o aspecto da separação e da hierarquia, configurados por linhas arbitrárias demarcadas representando a especialização e a concentração de saberes e poderes, a referência teórica para apoiar o estudo desenvolvido para a pesquisa é Pierre Bourdieu.A decisão para a escolha foi determinada em virtude das suas investigações analisando os sistemas simbólicos e pela formulação construída para a Teoria Geral da Economia dos Campos (BOURDIEU, 1986; 1989).

Portanto, o teórico constitui a fonte para apontar no campo da Museologia as significações elaboradas por esse espaço e, ainda, deixar margem para futuras reflexões acerca da inflexão simbólica e das relações que são estabelecidas. Especialmente quando os estudos da Museologia focalizam o contexto classificado e denominado de Bens Culturais, ou "bens simbólicos". E para a classe dos Bens a dimensão da cultura tem atribuído um valor caracterizado pelo seu reconhecimento na categoria Patrimônio, isto é, representação da herança cultural, tema que tem sido na ação da Museologia interpretado e identificado como Patrimônio Musealizado (Museus), denominação que a autora do artigo usa em posição semelhante ao que ela se permite designar como Patrimônio Musealizável ${ }^{3}$, ou seja, os bens/patrimônio ainda não submetidos à interpretação da ação museológica que, no entanto, pelo aspecto cultural que lhes foi outorgado estão aptos a serem modelados conforme a feição elaborada pela Museologia para os Museus.

No entanto, ao tratar do sentido emprestado à expressão bens simbólicos é preciso não esquecer a afirmativa de Bourdieu (I986, p. I02) que alerta, apontando, serem constituídos por "realidade com dupla face - mercadorias e

3 Em razão da condição simbólica que as representações dos Bens encerram e tendo como intuito distinguir as condições pelas quais é possível reconhecer o Patrimônio que a Museologia trata, quando abordo em artigos ou em aulas as estreitas relações entre Museologia e Patrimônio venho, ao longo dos anos, aplicando dois termos que refletem e esclarecem de modo simples as duas situações existentes: Patrimônio Musealizado ao já estar enquadrado na categoria Museu; e Patrimônio Musealizável na medida em que apresenta potencial para o processo de musealização. 
significações". No aspecto mercadoria em razão de ter havido no espaço onde os bens circulam a valorização sob a lógica capitalista do consumo. $E$ no que tange às significações também é possível lembrar outro teórico, Lier (I972, p. I52), que afirmou serem os "signos definidos em uma sociedade" formas criadas para dar conta das significações que se fazem ver nas práticas.

\section{Campo do conhecimento da Museologia e a presença do poder simbólico}

O Campo do Conhecimento é considerado território de disciplinas acadêmicas que se afigura como delimitado por 'linhas invisíveis' cuja significação indica a separação desenhada por diferentes conhecimentos. Tal forma de representação caracteriza diversas áreas de significação da realidade demarcadas por 'fronteiras' conceitualmente estabelecidas e institucionalizadas no universo cultural. Nesses campos institucionalizados do saber, socialmente aceitos e reconhecidos, fundamentados na ideia da autoridade, da legitimidade, da hierarquia, a estrutura se sustenta na relação de interdependência entre saber e poder político, o "poder simbólico" (BOURDIEU, 1986, p. 183-202), poder dominante na construção da(s) realidade(s) dos grupos sociais. A imagem construída pelas linhas arbitrárias estabelecidas, as fronteiras do conhecimento, demarcam um espaço de especialização e concentração de saberes e poderes.

Sendo um campo regionalizado de produção simbólica e representando a relação entre o poder e o saber expressa um lócus de "lutas" em cujo espaço as condições e os critérios de legitimação dos membros na hierarquia do campo foram estabelecidos. Identifica-se essa modalidade de ação como "relações informais do poder" (BOURDIEU, I 989, p. I I, 15, 64) que, atuando de modo sutil, passam praticamente despercebidas por refletirem a condição de naturalização resultante e estabelecida pelo processo de dominação enraizado, paulatinamente, pelo poder simbólico no contexto social.

O poder simbólico que é da ordem do arbitrário é, assim, explicado por Bourdieu (1989, p. 14-15, grifo nosso):

[...] um poder de fazer coisas com palavras. E somente na medida em que é verdadeira, isto é, adequada às coisas, que a descrição faz as coisas. Nesse sentido, o poder simbólico é um poder de consagração ou de revelação, um poder de consagrar ou de revelar coisas que já existem. Isso significa que ele não faz nada? De fato, como uma constelação que começa a existir somente quando é selecionada e designada como tal, um grupo - classe, sexo, religião, nação - só começa a existir enquanto tal, para os que fazem parte dele e para os outros, quando é distinguido segundo um princípio qualquer dos outros grupos, isto é, através do conhecimento e do reconhecimento" (grifo nosso).

E o campo do conhecimento, domínio específico da realidade social no qual se exercita o poder simbólico, é dotado de características merecedoras de abordagem no presente texto cujo foco é o território museológico. E, dessa maneira, está sendo apresentado o que se considera relevante, enquadrando-se no 'convite' que foi feito às reflexões nomeadas no título do artigo.

2.a) - CAMPO - Formalizado como esfera autônoma de organização, de produção e circulação de bens culturais, o mesmo que "bens simbólicos" (BOURDIEU, 1986, p. 102). 
A autonomia de um campo do conhecimento é o resultado de longo processo histórico traçado para sua constituição e está sedimentada na figura nomeada de "depuração" (BOURDIEU, 1989, p. 285-286). Consiste na construção elaborada pelas condições de isolamento mantidas em relação a outras "instâncias de legitimidades externas", por conseguinte, evitando qualquer interferência que possa ser considerada estranha, que se venha intrometer na caracterização do seu perfil e abalar sua estrutura de poder. Em decorrência, nas palavras do mesmo autor (BOURDIEU, 1986, p. I00), o campo passa a ser regido por orientações e "padrões que lhe são próprios". Em virtude disto, torna-se apto a exercer sua independência frente a imposições das demais esferas.

A condição independente ou autônoma, exatamente e de modo exclusivo, é o elemento que distingue e define um campo. Exerce o poder capaz de validar suas leis, seus princípios e suas normas. É o que lhe imprime caráter e o legitima tanto em nível interno como externo.

Nesse aspecto e em se tratando do domínio museológico é possível apontar, tomando como exemplo, as disciplinas que lhe são próprias e ostentam na designação a marca distintiva do campo: Museologia Aplicada a Acervos, Museografia.

2.b) - CAMPO - Espaço, ao mesmo tempo, da organização, da produção e dos instrumentos para apropriação dos bens simbólicos, o conjunto patrimonial que reflete e consubstancia a Herança Cultural, perspectiva integradora dos bens da coletividade sob a imagem do pertencimento, representação na qual se pode reconhecer a ambiência do Patrimônio Musealizável e do Patrimônio Musealizado.

O comportamento lastreado pelo poder simbólico facultando produzir e apropriar-se, enquadra-se na imagem de Bourdieu indicativa do encontro que se dá entre os "cérebros ou consciências" e as "coisas" (BOURDIEU, 1989, p. 176), produzindo e reproduzindo o princípio básico que estabelece a realidade (simbólica) para o campo, movimentando-o.

E a dinâmica que o move provém da combinação entre o que é construído e o que é praticado no domínio do conhecimento. Envolve e focaliza a junção entre as atitudes específicas do campo e o universo social que o representa.

O procedimento diz respeito ao processo que abrange o Juízo / a Atitude -- eivado de significações, de conteúdo simbólico -- em facetas que tanto agem na criação do campo quanto as que são por ele criadas e capazes, também, de ajustarem-se em movimentação permanente.

Quanto à especificidade do processo está marcada nas convenções, nos atributos, nos valores que revestem a forma cultural compreendida como "forma simbólica" (CASSIRER, 200 I, p. 36) no ambiente referente à "formação cultural" (CHARTIER, I990, p. I3, I8) e registra o que se identifica na modalidade de um juízo como o artístico, o juízo religioso, o juízo científico e o que fala de perto ao tema em pauta: o Juízo Museológico.

Ao apontar o juízo e a atitude correlata, torna-se relevante destacar sob perspectiva intelectual e operativa as proposições que, no espaço do conhecimento Museologia, formalizam os referenciais constitutivos do estatuto do campo.

\section{2.b.I) Musealização.}

É um processo institucionalizado de apropriação cultural. Imprime caráter específico de valorização a elementos de origem natural e cultural. Estabelece sua caracterização identificando formas interpretativas materiais e imateriais da humanidade às quais imprime a interpretação de testemunhos que referenciam as existências e identidades. Considerados como documentos da realidade são 
determinados como objeto de tratamento científico pela Museologia, portanto adotados sob outra percepção da realidade, sendo reconhecidos na categoria dos bens simbólicos e integrados ao domínio do Museu, logo, ao contexto do patrimônio musealizado.

A musealização consigna um juízo / atitude enlaçando o plano conceitual e a prática que se pode executar indistintamente no local no qual está situada a coisa - musealização in situ -- quanto realizando a sua transferência para outro espaço - musealização ex situ. Em qualquer das circunstâncias, a interferência apropriadora do poder detido pelo campo altera a realidade (da coisa) ao estabelecer um novo contexto de existência.

A musealização para socialmente ser concretizada envolve a institucionalização, pois implica em "singularizar juridicamente" ou em "uma decisão administrativa" ${ }^{4}$ (DESVALLÉES, 2000, p. 7I), atribui um "estatuto patrimonial" ${ }^{5}$ (DESVALLÉES; MAIRESSE, 20II, p. 625) para a apropriação cultural da coisa a ser musealizada (objeto, espécime, sítio, ou qualquer outro elemento que se adéqüe ao processo) e estabelece um estado museológico, o "estatuto museal” 6 (DESVALLÉES; MAIRESSE, 2010 , p. 48), outorgado pelo enfoque especializado da Museologia.

De um ponto de vista museológico, a musealização é uma operação que tende a extrair, fisicamente e conceitualmente, uma coisa de seu meio natural ou cultural de origem e dar-lhe um estatuto museal, para transformá-la em musealium ou museália, "objeto de museu", ao fazê-la entrar no campo [...]. (DESVALLÉES; MAIRESSE, 20I0, p. 48; $20 \mathrm{Il}$, p. 25 I, grifo do autor $)^{7}$

2.b.2) Musealidade.

Em consonância com o processo de musealização tem-se a musealidade para assinalar a qualificação de um "valor cultural" atribuído ao bem (DESVALLÉES, 2000, p. 72), (DESVALLÉES; MAIRESSE, 20I I, p. 256).

Termo proposto pelo museólogo checo Zbyněk Stránský para designar o valor cultural ou a qualidade de uma [verdadeira] coisa musealizada. [...] A razão pela qual este objeto foi selecionado é seu valor de testemunho da realidade que documenta. [...] Esse valor é chamado 'musealidade', porque não é mais a realidade (DESVALLÉES; MAIRESSE, 2011, p. 625) ${ }^{8}$

A musealidade faz-se entendida detentora de 'qualidade' que imprime e configura efetivando a mudança da realidade dita de origem por outra situação: a construção da 'realidade' musealizada.A musealidade é um atributo que assume caráter definidor e valorativo, uma 'especificidade' outorgada por condição do campo da Museologia pela sua via expressiva de representação, o Museu,

4 No original: singulariser juridiquement; une décision administrative

5 No original: statut patrimonial.

6 No original: statut muséal.

7 No original: D'un point de vue museologique, la musealisation est l'operation tendant a extraire, physiquement et conceptuellement, une chose de son milieu naturel ou culturel d'origine et à lui donner un statut muséal, a la trans former en musealium ou musealie, "objet de musée”, soit a la faire entrer dans le champ [...].

8 No original:Terme proposé par le muséologue tcheque Zbyněk Stránský pour designer la valeur culturelle ou la qualité d'une [vrai] chose muséalisée. [...] La raison pur laquelle cet objet a été sélectionné est sa valeur de témoignage de la réalité qu'il documente. [...] Cet valeur est appelé "muséalité" car il ne s'agit plus de la realité 
elemento mediador junto ao meio social da percepção do real através da 'sua' realidade construída; assentada no elenco de bens culturais e naturais no seu espaço teórico e prático de 'ser' e, ao mesmo tempo, 'tratar' o patrimônio, isto é, a herança coletiva.

O trabalho da musealização conduz, no máximo, a dar uma imagem que não é um substituto da realidade a partir da qual os objetos foram selecionados. Este substituto complexo, ou modelo de realidade construído no seio do museu, constitui a musealidade, ou seja, um valor específico que emana das coisas musealizadas (DESVALLÉES; MAIRESSE, 2010, p. 49) ?.

2.b.3) Competência Cultural Museológica ou o respaldo social para a musealizar e comunicar os resultados.

A “competência cultural” (BOURDIEU, I 986, p. 25, 62; I989, p. 6I) também faz referência ao estatuto de um campo do conhecimento no contexto juízo / atitude que expressa a marca da presença do poder sob a forma simbólica. E o perfil exigido pelo campo para modelar a competência tem constituição de natureza político-institucional. É traçado pelo padrão que regula o comportamento relativo aos procedimentos museológicos componentes da trajetória profissional.

O desenho sob o ponto de vista dos movimentos que inspiram à teoria e exercitam a prática no espaço em questão, por exemplo, é ilustrado no plano teórico pelas pesquisas em Museologia, pois descortinam horizontes, conduzem ora a rumos conceituais novos ora reforçam os rumos já conhecidos, porém, em ambos orientam à consolidação científica do campo. E, assim, o fortalecimento do domínio se acentua nas duas circunstâncias. Com referência ao plano da prática vale destacar o âmbito que se convencionou nomear museográfico e no qual se pode citar na dinâmica do pensar e do agir do campo o processo de construção e realização das exposições museológicas - ambiência do museográfico - quando, então, a informação e a comunicação dirigidas aos diversos segmentos que formam o público de museu - os visitantes - passam a ser o ponto fundamental, prioritário para a interação.

No domínio qualquer que seja o olhar interpretativo lançado, modelo (teoria) ou ação (prática), a competência trabalha aliada ao espectro do conhecimento nos modos e nos ritmos das ocorrências. Está atrelada ao relacionamento entre o museu e a sociedade para a qual se coloca a serviço no atendimento a princípios éticos de conduta profissional que dizem respeito ao comportamento social do campo.

2.b.4) Linguagem de Especialidade - expressando ideias e procedimentos do campo.

A Linguagem de Especialidade, Linguagem Profissional, é outra modalidade pautada no poder simbólico e exercida no foco do estatuto de campo.É identificada e "se apoia [...] expressa por meio de termos [...] do discurso museológico [...] E a linguagem, manifestação cultural do sistema simbólico, consubstancia, ao lado dos agentes individuais e institucionais, um dos instrumentos de legitimação do campo" (LIMA, 2007).

A linguagem atua integrando e reforçando as ligações entre o corpo de agentes. Sua consistência se faz verificar pela compreensão das formulações pro-

9 No original: Le travail de muséalisation ne conduit, tout au plus, qu'à donner une image qui n'est qu'un substitut de la réalité à partir de laquelle les objets ont été sélectionnés. Ce substitut complexe, ou modèle de la réalité construit au sein du musée, constitue la muséalité, soit une valeur spécifique se dégageant des choses muséalisées. 
postas, não obstante as diferenças teóricas e metodológicas que os campos possam apresentar em meio a seus grupos; e há estreita relação entre a consistência terminológica e o caminho de consolidação do domínio do conhecimento.

A terminologia museológica confere às interrelações e aos produtos das comunidades do campo "sentido e valor" (BOURDIEU apud MICELI, I986, p. xii).Ao se constituir como língua especializada procede à comunicação entre pares com poder de disseminar a informação de cunho específico referida à área.

A Linguagem de Especialidade é elemento fundamental, instrumento básico de aplicação na comunicação científica do campo. E ao modo de um código só é compreensível para os 'iniciados', reforçando as fronteiras do conhecimento. Constitui a marca da "distinção" (BOURDIEU, 1989, p. II) conferida ao campo indicando sua especificidade.

Integra o que merece ser considerado patrimônio do campo e determina a (marca da) diferença entre as linguagens profissionais dos espaços do conhecimento (veja-se o exemplo dos termos / conceitos Musealização e Musealidade).

E o patrimônio do campo consigna o "capital cultural", o mesmo que “capital de bens simbólicos” (BOURDIEU, 1989, p. II6, I53), o conhecimento acumulado e amealhado merecendo ser preservado por representar a herança que, simbolicamente, pertence a todos os pares e os identifica como grupo, atuando como elemento de coesão.

2 c) CAMPO - Estrutura exigindo especialistas: os "produtores e empresários de bens simbólicos” (BOURDIEU, 1986, p. 100).

As formas culturais institucionalizadas e objetivadas de representação coletiva são fixadas no campo e encontram respaldo nas funções de representação (simbolização). A finalidade é atender aos padrões ditados pelo contexto de autonomia e juízos / atitudes.

Tais formas aparecem configuradas como "condições [...] de acesso à profissão, [...] quanto àquelas referentes à participação no meio especializado" (LIMA, 2003, p. 18). Em destaque estão os agentes que, tradicionalmente, são nomeados e reconhecidos como especialistas. São grupos constituídos por corpos sociais organizados que detêm domínio dos conteúdos da profissão, os conhecimentos da área. No traçado do campo fazem-se representar pelos profissionais da Museologia em duas vertentes: a dos agentes individuais e das entidades, os agentes institucionais.

Em se tratando da inserção no campo, o que se entende por representação social de cada um desses ramos, não se pode deixar de assinalar um dos exemplos do modelo em nível local que diz respeito às instituições de registro profissional, reguladoras do exercício prático e do padrão ético das condutas, entre outras condições da profissionalização. E, em nível internacional, as associações que congregam membros individuais e instituições de diversos países voltadas, também, para conduta ética além de disseminarem os conhecimentos do campo por meio de eventos, publicações, repositórios digitais locais e em sites na internet, entre outros recursos informacionais. No primeiro exemplo, no Brasil, o Conselho Regional de Museologia (COREM) e no último, o Conselho Internacional de Museus, International Council of Museums (ICOM).

No que tange aos agentes individuais que atuam no campo da Museologia, ainda, vislumbra-se uma distinção com relação ao exercício do poder simbólico no tocante ao que se entende por especialista no assunto e manifestada sob duas denominações no espaço do conhecimento.

Há a categoria Museólogo, no Brasil retratando uma condição profissional definida e regulamentada por instrumentos legais: Lei $n^{\circ} 7.287$, de 18 de dezem- 
bro de 1984 e Decreto ${ }^{\circ}$ 91.775, de I 5 de outubro de 1985; e que se credencia a partir da formação em cursos de graduação e de pós-graduação em Museologia com exercício respaldado pelo registro no COREM ${ }^{10}$. Deve-se dizer que é uma situação peculiar comparada aos demais países nos quais há pessoas que não só atuam nos museus como enfocam temas da Museologia sob perspectiva teórica, no entanto, sem o respaldo de instrumentos jurídicos de definição de igual teor e, em largo senso na literatura do campo, são agentes referidos como museólogos. E convém lembrar: cursos existentes fora do Brasil que podem apresentar o título ligado particularmente a Museologia/Museu e auferir a condição de formadores de museólogos, isto é, profissionais que dominem não só os conteúdos práticos como também os de ordem teórica, como é do conhecimento dos que atuam campo ainda são em número ínfimo, principalmente quando se toma como referência o Brasil cuja graduação em Museologia com os novos cursos criados marca sua presença de forma exponencial ".

A outra categoria está associada ao "membro individual" do ICOM e nomeada Profissional de Museu (icom.museum). A condição apontada no contexto internacional não determina para ingresso na Instituição que se tenha a qualificação de museólogo obtida pela formação, pelo estudo especializado em Museologia como se aplica no Brasil. $O$ contingente reúne diversos profissionais de outras áreas do conhecimento que contribuem com suas especialidades para o cotidiano da Museologia no processo de associação e troca de experiências entre campos do conhecimento.

A relação entre os saberes aparece visualizada, por exemplo, quando se depara com certos títulos entre os 31 Comitês Internacionais do ICOM (icom. museum): - Comitê Internacional para Educação e Ação Cultural, CECA, International Committee for Education and Cultural Action; -- Comitê Internacional para Documentação, CIDOC, International Committee for Documentation; -- Comitê Internacional para Museus e Coleções de Arqueologia e História, ICMAH, International Committee for Museums and Collections of Archaeology and History, entre outros.

E do mesmo modo a marca dos diversos conhecimento se faz inscrita nos nomes que vários museus ostentam como: Museu de Artes; Museu de Astronomia; Museu de História Natural e tantos outros que se apresentam.

$O$ assunto tratando da relação entre os campos focalizando as disciplinas e as áreas do conhecimento envolvidas no contexto museológico será tratado adiante, no tópico 3. Museologia compartilha experiências com outros campos.

2. d) - CAMPO - "campo de concorrência” (BOURDIEU, I989, p. 278) entre especialistas do conhecimento e as instâncias de legitimação dos bens simbólicos musealizados.

As representações da profissionalização que respondem pelo campo, agentes individuais e institucionais, atuam no papel de avalistas do poder simbó-

I0 Ao regulamentar-se a profissão de museólogo foi reconhecido o direito legal para enquadrar na categoria o profissional que, na ocasião, exercia atividade compatível e já cumprira na data da regulamentação o tempo mínimo definido pela lei no contexto da Museologia/Museu, independente da formação em curso específico.Trata-se do Museólogo registrado sob a classificação Provisionado.

I I Torna-se interessante mencionar a expansão ocorrida. No início do ano 2000, no Brasil só havia dois cursos de graduação (UNIRIO e UFBA, tendo sido o do Rio de Janeiro herdeiro do pioneiro curso do Museu Histórico Nacional). Hoje o número está rompendo a barreira da quinzena. Em se tratando da pós-graduação, cuja história é recente, além do curso de mestrado (2006) e doutorado (20I I) do Programa em Museologia e Patrimônio, PPG-PMUS UNIRIO/MAST, no Rio de Janeiro, foram criados: o mestrado (20I2) do Programa Interunidades em Museologia, USP, em São Paulo; e o mais novo em Salvador, Programa em Museologia, UFBA com início previsto para 20 I3.2.Tal situação, ao que parece, indica não só o interesse pelo assunto Museologia mas, sobretudo, a necessidade da formação profissional pela via acadêmica. 
lico emprestando valor, outorgando "legitimidade cultural" (BOURDIEU, I986, p. I87; 1989, p. 279) aos movimentos competitivos que integram o processo de economia do domínio.

Nesse ambiente assume relevância a "lei do campo" (BOURDIEU, 1986, p. 187; 1989, p. 279), conjunto de regras de coexistência que subentende o exercício da competitividade (rivalidade) entre os agentes. Em face disto, instaura nos pares e nas entidades a condição de concorrentes pela "dinâmica da competição do conflito por crédito" (HOCHMAN, 1994, p. 228), conjuntura que combina o juízo, a atitude e o mérito à concessão, por exemplo, de aportes financeiros para as realizações da área (pesquisas, bolsas, equipamentos, eventos, etc.). A mescla de juízo, atitude e mérito está alicerçada na harmonização entre a qualidade e a quantidade de fatores que mensuram a trajetória profissional de cada participante.

No cenário de concorrência enfocando a temática dos bens simbólicos musealizados (patrimônio) avultam os espaços de competência para legitimação cultural, estabelecendo as posições e as disposições profissionais e institucionais emanadas da "lei”. Na caracterização do campo há instâncias culturais que, niveladas na estrutura simbólica do território, detêm o poder de reafirmar a força de representação do Museu no contexto social: as "instâncias de consagração, de difusão e de reprodução dos produtores e dos consumidores" (BOURDIEU, 1986, p. II6-135) determinando para o Museu, segundo o mesmo autor, o caráter de "capital simbólico de reconhecimento" por estar presente em três instâncias definidoras do desenho do campo.

As "instâncias de consagração" espelham a competição pela legitimidade cultural dirigida aos destinos da "vida intelectual" da área (conforme o autor na mesma obra). Atuam no papel voltado a favorecer o surgimento de novas propostas conceituais e de práticas, ainda podem reforçar o pensamento e a ação tradicionais em permanente e estimulante jogo.

As exposições museológicas pela repercussão pública tradicionalmente consignada no processo informacional e comunicacional; a produção científica resultante das pesquisas pela visibilidade interna e externa que imprime pela disseminação da informação; as distinções ou diferenças (BOURDIEU apud MICELI, 1986, p. $x$ ) relativas ao valor atribuído ao caminho profissional, como por exemplo, a medalha do Mérito Museológico; entre outras formas culturais, exprimem o significado consagratório que a primeira categoria de instância determinada pelo teórico francês encerra.

As "instâncias de difusão" tomam por base para seleção a legitimidade que Bourdieu (1986, p. I20) denomina "propriamente cultural”, isto é, as atividades culturais variadas que, embora similares as de outras áreas como os eventos técnicos, os cursos, as palestras, as edições (em diversos suportes/mídias), os concertos, etc., tornam-se identificadas pela responsabilidade, pela competência da realização museológica e são chanceladas como 'produto de museu', o que empresta o sentido (distintivo, diferenciador) da especificidade.

Por último, as "instâncias de reprodução dos produtores e dos consumidores" comportando os aparelhos de produção simbólica de acesso à formação e ao aprimoramento profissional, configurando o sistema de ensino da Museologia nos níveis universitários da graduação e da pós-graduação. Espelham o processo de reprodução cultural, aparato de cunho ideológico.

2 e) - CAMPO - Zonas estratégicas: campo disciplinar e manutenção do poder simbólico que instaura a musealização.

Nas áreas do conhecimento pode ocorrer que qualquer disciplina identificada como colaboradora pela conjugação de estudos focalizando o mesmo 
objeto -- e em determinada situação nos moldes do "trabalho de fronteira" 12 (KLEIN, 1996, p. 60); atue perpetrando movimentos que podem ser percebidos como ameaça de 'invasão' no campo que recebe a contribuição disciplinar.

O comportamento alcança um resultado que poderá forçar e precipitar outra movimentação do poder simbólico nos limites das fronteiras disciplinares.

A ação do campo ao sentir-se ameaçado é representada por meio da luta simbólica e executada pela via de uma postura defensiva baseada em estratégias de negociação como caminho para manutenção do poder simbólico, não fosse tal postura reativa uma formulação gerada pela sutileza e invisibilidade de que se reveste o poder, como frisa Bourdieu ao longo das suas pesquisas que tratam do tema. Ele nomeou esse modo de reagir de "formas eufemizadas de luta", uma imagem que ilustra adequadamente e reproduz o que ocorre.

O procedimento tático é não entrar em confronto aberto e lançar mão de estratégias para uma solução sem danos, sempre que possível, a cavaleiro da situação.

No caso em pauta dá-se uma abertura consentida como se fora uma dilatação das fronteiras que operando em movimentos de "deslimites" (LIMA, 2003: 57) desenha espaços considerados permeáveis e desenvolve o intercâmbio disciplinar (KLEIN, 1996: 2), configurando áreas ao modo de "zonas comuns" de convívio (LIMA, 2003: 56) para que venham a permitir a ação combinada, escamoteando embates que poderiam gerar perdas significativas de poder no domínio. Isto se compreende em razão dos novos espaços abertos atuarem expressando o sentido de "zonas de acordo" (LIMA, 2003: 64-66) entre conhecimentos, capacitando que haja integração entre os grupos profissionais heterogêneos que ali estão atuando.

A composição de zonas de concordância e comunidades mistas do conhecimento que se reorganizam para compartilhar e manter o poder pode ser vista como um retrato do campo museológico, em tudo similar a qualquer outro campo na mesma situação. Trata-se de um modo de subsistir formalizando um ambiente de convivência entre variados conhecimentos e agentes, isto em virtude da comunidade dita museológica estar composta pelos museólogos de formação e pelos demais profissionais de Museus oriundos dos outros campos.

As modalidades zonas de intercâmbio, zonas comuns, zonas de acordo são espaços profissionais que conformam relações de cooperação entre os campos do conhecimento e seus membros.

\section{Museologia compartilha experiências com outros campos}

O campo da Museologia que se estruturou faz pouco mais de meio século encontra nos museus existentes há centena de anos o ponto de convergência de olhares internos e externos ao seu domínio. E o domínio do conhecimento museológico tem comportado atuar relacionando-se com outros campos quer nas questões que importem em discurso, quer nas que se prestem ao ato, portanto, perpassando os extratos da teoria e da prática.

O envolvimento combinando comunidades e conhecimentos disciplinares no espaço cotidiano da Museologia permite considerar que a ocorrência dos mencionados trabalhos de fronteira, ao longo dos tempos, é situação que favorece trocas entre as unidades do conhecimento, contemplando, compatibilizando e completando as necessidades impostas pelas questões surgidas como resultado das diferenças disciplinares. $\mathrm{E}$ em tais ambientes colaborativos (mesmo pela força do traçado estratégico) são as comunidades mistas, heterogêneas na

12 No original: boundary work. 
sua formação, que se tornam aptas para desenvolver a competência teórica e de ação visando atender e tratar os problemas que apresentam múltiplas feições.

No panorama de um espaço de simbolização representado pelo campo do conhecimento e no contexto de espaços e negociações do poder simbólico é interessante e oportuno lembrar a modalidade de desenvolver encontros e harmonizar saberes - uma estratégia articulada para o ganho. No caso da Museologia o foco se volta para as relações desenvolvidas pelo campo (território da musealização) com os outros domínios por meio da contribuição de "disciplinas cooperantes" (JAPIASSU, I 976, p. 89) que atuam como conhecimentos aliados, sobretudo em atividades ligadas a projetos operacionais que a musealização desenvolve.

Os campos / disciplinas contribuem com suas perspectivas interpretativas, inclusive, podendo trazer aportes conceituais e/ou metodológicos e agir no campo museológico como aplicação disciplinar, modalidade de ação que em determinadas circunstâncias, conforme os estudos da interdisciplinaridade, pode em perspectiva epistemológica evoluir para a composição interdisciplinar.

E como meio de ilustração das disciplinas cooperantes são apresentados alguns exemplos de campos / disciplinas que já marcaram sua presença como saberes aliados ao campo museológico ao longo do seu percurso de consolidação, ora no contexto da formação acadêmica da Museologia, ora no quadro das pesquisas e demais estudos realizados no âmbito dos Museus.

Administração (em Museus) -- Antropologia -- Arqueologia - Arquitetura (de Museus e de Exposições) -- Arquivologia -- Arte Sacra -- Artes Plásticas - Astronomia -- Biblioteconomia -- Botânica -- Ciência da Informação $(\mathrm{Cl})$ - Ciências da Computação -- Comunicação / Comunicação Visual - Desenho Industrial -- Documentação / Documentação em Museus ou Documentação Museológica (contexto da Cl)- Ecologia -- Educação Ambiental -- Educação Patrimonial -- Etnologia / Etnografia -- Estética -- Diplomática -- Filatelia -Filosofia -- Física -- Heráldica -- História - História da Arte - História das Ciências -- História Militar e Naval - Iconografia -- Informática - Informação em Arte (contexto da Cl) -- Memória Social -- Mineralogia - Música - Numismática -- Paleontologia -- Pedagogia / Educação em Museus / Educação Artística -- Preservação / Conservação/Restauração -- Química -- Semiologia / Semiótica -- Sigilografia -- Sociologia -- Webdesign -- Zoologia ${ }^{13}$.

\section{Encerrando}

A leitura analítica que se fez do campo do conhecimento da Museologia recortou as características que se apresentam como imagens determinantes do seu perfil como instaurador do poder simbólico da ordem da musealização do(s) patrimônio(s).

$\mathrm{Na}$ tarefa para realizar a interpretação dos elementos considerados marcantes no domínio foram aplicados conceitos selecionados dos estudos teóricos realizados por Pierre Bourdieu que abordam o exercício do poder simbólico no contexto dos espaços do saber.

A escolha da proposição do autor permitiu identificar a presença de tal força perpassando as representações construídas pelo campo, as significações que são expressas, as relações que estabelece e as variadas circunstâncias que envolvem no ambiente social a forma cultural Museu.

Os indicadores para análise que foram referidos à seara museológica trataram das peculiaridades do campo nos aspectos que estão ligados aos bens

13 O elenco atual, ligeiramente modificado, tomou por base a relação que consta da tese da autora do artigo podendo ser conferido em: LIMA (2003). 
culturais, a entidades/instituições e aos profissionais no modelo cultural da apropriação simbólica.

É nesse desenho do campo simbólico que se deve destacar o discurso e a prática nas modalidades do constructo musealização e do corolário musealidade; na legitimidade dos modos pelos quais se revestem os juízos atribuídos e as atitudes pertinentes; no lastro dado pela competência museológica; no domínio de uma linguagem exclusiva, linguagem de especialidade, expressando as singularidades da teoria e da prática; na identidade da profissionalização caracterizando seus agentes; nos referenciais da distinção definindo os grupos, estabelecendo a perspectiva da competição e destacando a legitimação pelas instâncias; nos procedimentos estratégicos para integridade das fronteiras disciplinares e nas formalizações de suas adequações desenvolvidas em experiências conjuntas.

A visão que surgiu está mostrando os procedimentos que se analisou marcados pela ação do poder simbólico e veio a indicar que esse instrumento intangível de marcante presença é elemento ativo no caminho da consolidação dos campos do conhecimento. Deixando perceber que os campos usufruem estrategicamente desse poder visando múltiplos resultados para benefício.

$\mathrm{O}$ assunto estimula continuar a pesquisar.

\section{Referências}

BOURDIEU, Pierre.A economia das trocas simbólicas. Tradução de Sérgio Miceli. 2. ed. São Paulo: Perspectiva, 1986. (Estudos).

BOURDIEU, Pierre. O poder simbólico. Lisboa: Difel, 1989. (Memória e sociedade). BRASIL. Decreto $n^{\circ}$ 91.775, de 15 de outubro de 1985. Diário Oficial [da] República Federativa do Brasil, Poder Executivo, Brasília, DF, I6 out. 1985. Seção I, p. 15068. Disponível em: <http://www2.camara.leg.br/legin/fed/decret//980-1987/ decreto-9|775-I5-outubro-I985-44I776-publicacaooriginal-I-pe.html>. Acesso em: 21 jan. 2013.

BRASIL. Lei $n^{\circ}$ 7.287, de 18 de dezembro de 1984. Diário Oficial [da] República Federativa do Brasil, Poder Executivo, Brasília, DF, 19 dez. I 984. Seção I, p. 19033. Disponível em: <www.planalto.gov.br/ccivil_03/Leis/L7287.htm>. Acesso em: 21 jan. 2013.

CASSIRER, Ernest. A filosofia das formas simbólicas: a linguagem. Tradução Marion Fleischer. São Paulo: Martins Fontes, 200I. (Tópicos, I).

CHARTIER, Roger.A história cultural entre práticas e representações.Trad. Maria Manuela Galhardo. Lisboa: DIFEL, 1990. (Coleção memória e sociedade).

CONSELHO FEDERAL DE MUSEOLOGIA (Brasil). Home. Disponível em: $<$ http://cofem.org.br/>.Acesso em: 17 jan. 2013.

DESVALLÉES, A. Terminología museológica: proyecto permanente de investigación. Rio de Janeiro:Tacnet Cultural.2000. I CD ROM. (ICOFOM, ICOFOM LAM (ICOM). DESVALLÉES, A.; MAIRESSE, F. (Ed.). Concepsts clés de muséologie. [S.I.]: Armand Colin; ICOFOM. 20I0. Disponível em: <http://icom.museum/fileadmin/ user_upload/pdf/ Key_Concepts_of_Museology/Museologie_Francais_BD.pdf> Acesso em: 27 jan. 2013.

DESVALLÉES, A.; MAIRESSE, F. (Ed.). Dictionnaire encyclopedique de museology. Paris:Armand Colin, Centre Nacional du Livre, 20I I. 2 v.

GEERTZ, Clifford. A interpretação das culturas. Rio de Janeiro: Guanabara-Koogan, 1989. 
HOCHMAN, Gilberto. A ciência entre a comunidade e o mercado: leituras de Kuhn, Bourdieu, Knorr-Cetina e Latour. In: PORTOCARRERO, Vera (Org.). Filosofia, história e sociologia das ciências l: abordagens contemporâneas. Rio de Janeiro: Fiocruz, 1994. p. 199-23I.

INTERNATIONAL COUNCIL OF MUSEUMS - ICOM, I2., 1977. General Assembly of ICOM. Resolution no. 7: museological terminology. Moscow, 1977. Disponível em: <http://icom.museum/the-governance/general-assembly/resolutions-adopted-by-icoms-general-assemblies- 1946-to-date/moscow-1977/>. Acesso em: 27 jan. 2013.

INTERNATIONAL COUNCIL OF MUSEUMS - ICOM. The international committees of ICOM. Disponível em: <http://icom.museum/the-committees/international-committees/>. Acesso em: 27 jan. 2013.

INTERNATIONAL COUNCIL OF MUSEUMS. Interdisciplinarity in Museology - ICOM. Museological working papers: a museological journal on fundamental museological problems. France, Sweden: ICOM, 198I-82. Disponível em: <http://network.icom.museum/fileadmin/user_upload/minisites/icofom/pdf/ MuWoP\%202\%20(198I)\%20Eng.pdf>. Acesso em: 30 jan. 2013.

JAPIASSU, Hilton. Interdisciplinaridade e patologia do saber. Rio de Janeiro: Imago, 1976. (Série logoteca).

KLEIN, Julie Thompson. Crossing boundaries: knowledge, disciplinarities, and interdisciplinarities. Charlottesville: University Press of Virginia, 1996. (Knowledge: disciplinarity and beyond).

LIER, Henry van. Objeto e estética. In:MOLES,Abraham et al. Semiologia dos objetos. Petrópolis:Vozes. 1972. p. I27-I56. (Coleção novas perspectivas em comunicação, 4). LIMA, Diana Farjalla Correia.Acervos artísticos e informação: modelo estrutural para pesquisas em artes plásticas. In: PINHEIRO, Lena Vânia Ribeiro; GONZÁLEZ de GÓMEZ, Maria Nélida (Org.) Interdiscursos da ciência da informação: arte, museu e imagem. Rio de Janeiro: IBICT, 2000. p. I7-39.

LIMA, Diana Farjalla Correia. Ciência da informação, museologia e fertilização interdisciplinar: informação em arte um novo campo do saber. 2003. 358 f. Tese (Doutorado)-Programa de Pós-Graduação em Ciência da Informação, Escola de Comunicação, Universidade Federal do Rio de Janeiro/UFRJ, 2003. Disponível em: <http://tede-dep.ibict.br/tde_busca/arquivo.php?codArquivo=21 >. Acesso em: 30 jan. 2013.

LIMA, Diana Farjalla Correia. Museologia e patrimônio interdisciplinar do campo: história de um desenho (inter)ativo. In: ENCONTRO NACIONAL DE PESQUISA EM CIÊNCIA DA INFORMAÇÃO - ENANCIB, 8., 2007, Salvador. Anais... Salvador:ANCIB; PPGCI-UFBA, 2007. Disponível em: <http://www.enancib.ppgci.ufba.br/artigos/DMP--060.pdf>. Acesso em: 28 jan. 2013.

LIMA, Diana Farjalla Correia. Museologia-museu e patrimônio, patrimonialização e musealização: ambiência de comunhão. Boletim do Museu Paraense Emílio Goeldi. Ciências Humanas - Museologia e Patrimônio, v. 7, n. I, p. 3I-50, jan./abr. 2012 Disponível em: <www.scielo.br/pdflbgoeldi/v7n I/a04v7n I.pdf>.Acesso em: I 7 jan. 2013. LIMA, Diana Farjalla Correia. Museu, poder simbólico e diversidade cultural. Museologia e Patrimônio, Revista Eletrônica do Programa de Pós-Graduação em Museologia e Patrimônio, v. 3, n. 2, jul./dez. 2010. p. 16-26. Disponível em: $<$ http://revistamuseologiaepatrimonio.mast.br/index.php/ppgpmus/article/ viewFile//67//61>. Acesso em: 17 jan. 2013.

LIMA, Diana Farjalla Correia; COSTA, Igor Fernando Rodrigues da. Ciência da 
informação e Museologia: estudo teórico de termos e conceitos em diferentes contextos: subsídio à linguagem documentária. In: ENCONTRO NACIONAL DE ENSINO E PESQUISA DA INFORMAÇÃO - CINFORM, 7., 2007, Salvador. Anais... Salvador: Instituto de Ciência da Informação, Escola Politécnica-UFBA, 2007. Disponível em: <http://www.cinform.ufba.br/7cinform/soac/papers/adicionais/DianaLima.pdf>.Acesso em: 28 jan. 2013.

MICELI, Sergio. Introdução: a força do sentido. In: BOURDIEU, Pierre. A economia das trocas simbólicas.Tradução Sergio Miceli. São Paulo: Perspectiva, 1986. (Estudos). SOLA, Tomislav. Concept et nature de la muséologie. Museum, v. 39, n. I53, p. 45-49, 1987.

STRÁNSKÝ, Z. Z. Documents de travail en museologie (DOTRAM). MUWOP: Museological Working Papers: Museology: Science or just practical museum work?, v. I, p. 42-44, I 980.

Artigo recebido em fevereiro de 20/3. Aprovado em abril de 2013 